\title{
Effective Heat Transfer Design for Solid and Cavity wall configuration
}

\author{
Amenyah $\mathbf{W}^{1}$, Kweku Govi $\mathrm{D}^{2}$ and Acakpovi $\mathrm{A}^{3 *}$ \\ ${ }^{1}$ Department of Mechanical Engineering, Accra Technical University, Ghana \\ ${ }^{2}$ Department of Mechanical Engineering, Accra Technical University, Ghana \\ ${ }^{3}$ Department of Electrical/Electronic Engineering, Accra Technical University, Ghana
}

Submission: April 25, 2017 , Published: June 05, 2017

*Corresponding author: Acakpovi A, Department of Electrical/Electronic Engineering, Accra Technical University, Ghana, Email: acakpovia@gmail.com

\begin{abstract}
This paper seeks to outline good practice in the design, installation and operation of building cooling systems. It encompasses the discussion on the different types of cooling systems that must be applied for particular needs. The paper also deals with the philosophy of building heat gain, the methodology in the prediction of cooling load energy and ultimately the importance of optimizing heat transfer. In the methodology section, Fourier's law was used to design the cooling systems for a solid wall and a cavity wall of same area made from material of similar heat transfer coefficient. Results showed that the cavity wall permitted less heat transfer into the confined space hence less electricity required to cool it. It is recommended therefore that, large public buildings should be designed in this manner so as to reduce the need for unnecessary electrical power to maintain them.
\end{abstract}

Keywords: Heat transfer; Cooling systems; Fourier law; Building design; Solid wall; Cavity wall

Abbreviations: UHI: Urban Heat Island; IEHE: Intensifies Extreme Heat Events

\section{Introduction}

Fossil fuel burning contributes to the pollution of the atmosphere leading to a wide range of damage both to public health and the environment. Increased atmospheric concentration of $\mathrm{CO}_{2}$ caused by burning fossil fuels has increased global temperature therefore energy efficiency improvement has the benefit of reducing global warming. Emissions as a result of burning fossil fuels contribute to SOx and NOx which are both contributors of acid rain. Thermal sources of producing electricity provide typically 30 to $50 \%$ efficiency, therefore excessive consumption could lead to 2 to 3 times the $\mathrm{CO}_{2}$ emissions per delivered $\mathrm{kWh}$ than the fossil fuel consumed. Effective heat transfer design is necessary to optimize electrical supply needed for cooling systems to work efficiently and at a reduced cost in public buildings, especially in a hot environment like West Africa.

Living in hot and humid climates requires that enough provision of adequate cooling is made for the greater part of the year to enable the maintenance of good health and comfort. Some consumers presume that 'central cooling' is luxury however, climate and weather variability in Africa make it to be seen as amongst the most vulnerable places in the world $[1,2]$. Heat wave is prolonged and periods of excessive hot weather are normally accompanied by high humidity $[3,4]$. It is measured relatively to normal or usual weather in a particular area as well as temperatures for a particular season [5]. Reports that, the warmest temperatures in Ghana ever recorded for a particular month was listed in Navrongo on the 6th of March, 2013 around $43^{\circ} \mathrm{C}$. Similar high values were recorded in Southern Morocco where daily anomaly of $10.4^{\circ} \mathrm{C}$ above normal was obtained in August. The range of $40^{\circ} \mathrm{C}$ to $43^{\circ} \mathrm{C}$ were similarly recorded in Sokoto, Maiduguri (both in Nigeria) and Vioolsdr if, South Africa [6].

The effect of global warming is the increase in the intensity, duration and frequency of heat waves with particular danger to urban populace. Meanwhile, the risks associated to health as a consequence varies between inhabitants due to the 
intrinsic human-specific peculiarities (characteristics) and other extrinsic determinants. It is evident that, health risks increase particularly in situations where Urban Heat Island (UHI) intensifies extreme heat events [7].

In recent times, the study to find the relationship between mortality and temperature increased greatly. A cold day's effect is easily seen whilst in contrast hot days may last for several weeks or months. In sub-Saharan Africa, mortality rates are high during the dry harmattan season than deaths in the rainy season [8]. Severe temperatures may be attributed to welldefined clinical symptoms such as heatstroke. Blood viscosity is increased due to high temperature which could result in cardiovascular events as stroke or heart attack [6]. Associates these happenings to the elderly since their temperature regulation are impaired? Heat waves kill very easily and when it occurs the elderly suffer many defects especially those having pre- existing illness [9]. Excess mortality is the result of cerebrovascular, cardiovascular and respiratory diseases. Even though the actual impact of heat wave is not actually certain, a greater proportion of the deaths occurs in persons who are susceptible persons and could have died in few months after anyway.

There is however no doubt that, the intensity of the heatwave increases the number of deaths due to severe weather. Some of the temperature- related mortality to vulnerability of heat indicators is as follows:
1. Disease profile and sex
2. Socio- economic status
3. Conditions of homes
4. Presence of air- conditioning
5. Behavior (clothing/ fashion/ style)

The above stated factors have equivalents in individuals just as those factors relating morbidity or mortality such as the socio- economic status at the time of death. Both population and individual level studies provide strong defense why for heart related mortality, the risk factor is age. Additionally, preserving the health of occupants of buildings calls for good and comfortable cooling of homes, adequate cooling of commercial, industrial and other public places. When people are extremely warm and uncomfortable, their performance will drop and ultimately affect the economy of their countries. Cooling a building to a comfortable temperature does not mean it is effectively cooled. Many buildings waste energy daily due jointly to poor design, poor installation, and poor operation and bad maintenance practices.

\section{Methodology}

Thermal comfort is achieved when the following environmental parameters are known; the mean radiant temperature, temperature of the air, air velocity and the relative humidity. They, in several ways affect the transfer of heat by radiation, evaporation and convection. Heat transfer by convection is a direct result of air velocity and air temperature as it occurs continuously even though values below $0.1 \mathrm{~ms}^{-1}$ are common. Radiant heat transfer is heavily influenced by the mean radiant temperature $\left(\mathrm{t}_{v}\right)$ for surfaces in room spaces. For rooms which are cubed in shape, an approximation of the mean radiant temperature can be obtained at the centre of the room by:

$$
\left(\mathrm{Q}_{\text {solar }}+\mathrm{Q}_{\text {int }}\right)_{\text {sensible }}=\mathrm{U} \times \mathrm{A} \times\left(\mathrm{T}_{\text {in }}-\mathrm{T}_{\text {out }}\right)(1)
$$

Where:

- Uis the heat transfer coefficient

- $\quad \mathrm{A}$ is the heat transfer area under consideration

- $\mathrm{T}_{\mathrm{in}}$ is the required indoor temperature

- $\mathrm{T}_{\text {out }}$ is the required outdoor temperature

From the above equation, the outside temperature at balance condition ( $\mathrm{T}_{\text {out,bal }}$ ) is given by

$$
\mathrm{T}_{\text {out,bal }}=\left(\mathrm{Q}_{\text {solar }}+\mathrm{Q}_{\text {int }}\right)_{\text {sensible }} /(\mathrm{U} \times \mathrm{A})
$$

For most designs however, air velocity of the building is below $0.1 \mathrm{~m} / \mathrm{s}$ which simplifies the above equation to:

$$
\mathrm{t}_{\mathrm{res}}=0.5 \cdot \mathrm{t}_{\mathrm{r}}+0.5 \cdot \mathrm{t}_{\mathrm{a}}
$$

Equilibrium is reached when the internal temperature is steady as heat gained to the building equal's heat lost from it. Internal environment becomes comfortable when the output of the cooling system is equal to or greater than the total effect of heat gained through the fabric of the building and ventilation heat gain. Fabric heat gain occurs by conduction through windows, roofs, walls and floors while ventilation gains include convective heat gains occurring as cold air is lost and replaced by hot air to the building.

Fourier's law states that; when a temperature gradient is established in a body, there is transfer of energy from the high temperature region to the low temperature region. Energy transfer by conduction occurs while the heat transfer rate per unit area is proportional to the normal temperature gradient. Fourier's law can be mathematically stated as:

$\mathrm{Q} / \mathrm{A}=\mathrm{k} \cdot \mathrm{dt} / \mathrm{dx}$

Or

$\mathrm{Q}=-\mathrm{k} \cdot \mathrm{A} \cdot \mathrm{dt} / \mathrm{dx}$

Where

- $\mathrm{Q}=$ heat transfer across the body

- $\mathrm{A}=$ the cross sectional area of the surfaces

- $\mathrm{dt}=$ the change in temperature 
- $\mathrm{dx}=$ the thickness of the wall

Heat loss due to building fabric is given by:

$$
\mathrm{Q}_{\mathrm{f}}=\mathrm{U} \times \mathrm{A} \times\left(\mathrm{t}_{\mathrm{ao}}-\mathrm{t}_{\mathrm{ai}}\right)
$$

Where

- $\mathrm{Q}_{\mathrm{f}}$ represents the fabric heat gain rate $(\mathrm{W})$

- $\quad \mathrm{U}$ is the thermal transmittance $\left(\mathrm{W} / \mathrm{m}^{2} \mathrm{~K}\right)$

- $\quad$ is the area $(\mathrm{m} 2)$

- $\quad \mathrm{t}_{\mathrm{ao}}$ is the outside air temperature $\left({ }^{\circ} \mathrm{C}\right)$

- $\quad \mathrm{t}_{\mathrm{a} o}$ is the internal air temperature $\left({ }^{\circ} \mathrm{C}\right)$

Similarly, ventilation heat gain is obtained from equation 6 as follow:

$$
\mathrm{Q}_{v}=0.333 \times n \times v \times\left(\mathrm{t}_{\mathrm{ao}}-\mathrm{t}_{\mathrm{ai}}\right)
$$

Where

- $\mathrm{Q}_{\mathrm{v}}$ is the ventilation heat gain $(\mathrm{W})$

- $\quad \mathrm{n}$ is the ventilation rate (air changes per hour)

- $\quad \mathrm{v}$ is the volume $\left(\mathrm{m}^{3}\right)$

From equations (6) and (7), it is established that ventilation loss and fabric loss are directly related to the difference between the external and internal air temperatures. It follows from the above that, energy consumption by cooling systems can be reduced by the creation of well insulated building envelope where the rates of ventilation for healthy living can be controlled to a minimum value. This can be achieved during design and installation stages by ensuring minimum thermal insulation standards which are expressed as U-values. Thermal transmittance (U-value) of a structure that is residential, commercial, a care center or a hospital becomes the main determinant for its steady-state heat gains/losses and this consequently determine the ability of the cooling or heating systems needed to keep the desired indoor design parameters with some additional parameters including external conditions.

\section{Design}

Two different scenarios of effective heat transfer system design are subsequently presented in the following paragraphs

\section{Scenario I}

Scenario I am concerned with the determination the rate of heat transfer by conduction per unit area through a solid wall of $125 \mathrm{~mm}$ (5”) thickness. Figure below represents the wall of the facility under discussion (Figure 1).

\section{Assumptions:}

1. The thermal conductivity of cement block is 2.0 $\mathrm{W} / \mathrm{m} \bullet \mathrm{K}$
2. The temperature of the outside environment in the area considered is approximately $35{ }^{\circ} \mathrm{C}$ whiles the desired internal temperature is considered to be $18^{\circ} \mathrm{C}$.

3. One dimensional conduction in the $\mathrm{x}$ - direction is considered

4. The analysis is conducted in steady- state conditions

5. Material properties remain constant

The heat flux may be computed subject to the conditions stated above from Fourier's Law as:

$$
\mathrm{Q}=\mathrm{A} \cdot \mathrm{k} \cdot\left(\mathrm{T}_{1}-\mathrm{T}_{2}\right) / \mathrm{X}
$$

\section{Application}

$$
Q=1 \cdot 2 \cdot(35-18) / 0.125
$$

$Q^{*}=272 \mathrm{~W}$

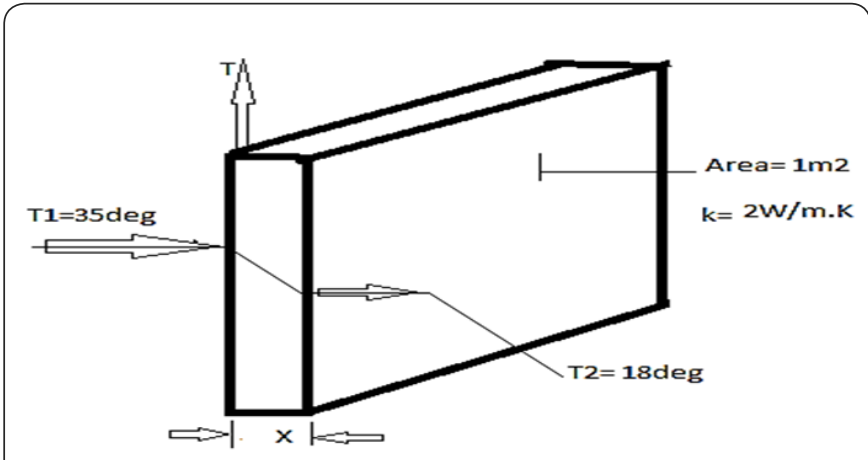

Figure 1: Model of heat transfer through a cement wall.

\section{Scenario II}

Scenario II solves a similar problem as in scenario I with different assumption and structure of the Wall (Figure 2) depict the new structure of the Wall to be considered;

\section{Assumptions}

- The thermal conductivity of cement block is 2.0 $\mathrm{W} / \mathrm{m} \bullet \mathrm{K}$.

- $\quad$ The temperature of the external surrounding, $\mathrm{T}_{1}=35$ ${ }^{\circ} \mathrm{C}$

- The interior temperature, $\mathrm{T}_{4}=18^{\circ} \mathrm{C}$

- One dimensional conduction in the $\mathrm{x}$ - direction is considered

- The analysis is conducted in steady-state conditions

- Material properties remain constant

- $\quad$ Let the wall be of cavity type (as shown in Figure 2a) with $X_{1}=35 \mathrm{~mm} ; X_{2}=55 \mathrm{~mm}$ and $X_{3}=35 \mathrm{~mm}$.

The overall thermal resistance shown in Figure 2bwill be obtained from: 


$$
\begin{aligned}
& \mathrm{R}=\mathrm{R}_{1}+\mathrm{R}_{2}+\mathrm{R}_{3} \\
& \mathrm{R}=\mathrm{X}_{1} /\left(\mathrm{k}_{1} \cdot \mathrm{A}_{1}\right)+\mathrm{X}_{2} /\left(\mathrm{k}_{2} \cdot \mathrm{A}_{2}\right)+\mathrm{X}_{3} /\left(\mathrm{k}_{3} \cdot \mathrm{A}_{3}\right)(12)
\end{aligned}
$$

Taking k values for wall and insulation thermal conductivity as follows: $\mathrm{k}_{\text {block }}=\mathrm{k}_{1}=2 \mathrm{~W} / m \mathrm{~K}, \mathrm{k}_{\text {insulation }}=\mathrm{k}_{2}=0.07 \mathrm{~W} / \mathrm{mK}$

Applying these values and bearing in mind that, $A_{1}=A_{2}=A_{3}=A$, we obtain:

$$
\begin{aligned}
& A \cdot R_{1}=A \cdot R_{3}=X_{1} / k_{1}=0.035 / 2=0.0175 \mathrm{~m}^{2} \mathrm{~K} / \mathrm{W} \\
& \mathrm{A} \cdot \mathrm{R}_{2}=\mathrm{X}_{2} / \mathrm{k}_{2}=0.055 / 0.07=0.7875 \mathrm{~m}^{2} \mathrm{~K} / \mathrm{W}
\end{aligned}
$$

For a series circuit, $\mathrm{Q} / \mathrm{A}$ is constant throughout and can be determined with equation (15)

$$
\mathrm{Q} / \mathrm{A}=\left(\mathrm{T}_{1}-\mathrm{T}_{4}\right) /(\mathrm{R} \cdot \mathrm{A})
$$

Application

$$
\begin{aligned}
& Q / A=(308-291) /(0.8207 \cdot 1)(16) \\
& Q / A=20.73 W / m^{2}
\end{aligned}
$$

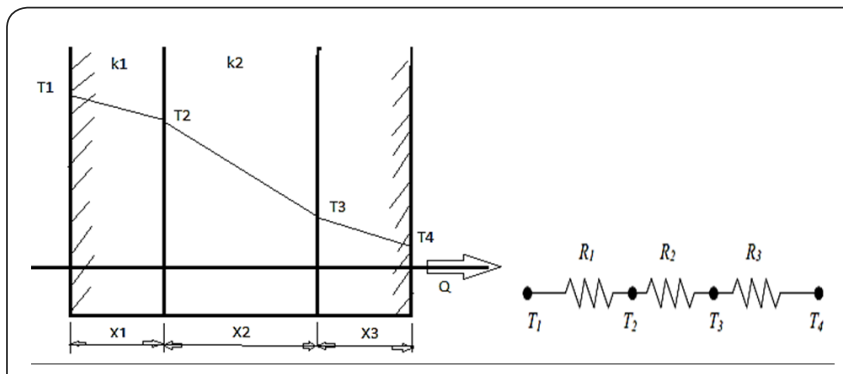

(a) Cavity wall (b)Thermal resistances put in series

Figure2: Model of heat transfer through a cavity and insulation wall.

\section{Discussion}

From the foregoing, heat transfer by conduction through the walls as per scenario I is 272 Watts whilst scenario II permitted the flow of only 20.73 Watts. This means that, the cavity wall with the insulation is better at preventing heat gain into a confined space. The amount of energy required to do this cooling is supplied by electricity from a thermal plant or a diesel generator which are all fossil fuels. Fossil fuels are finite and price of the commodity is ever- increasing. To practice "green or sustainable living", is either to switch to renewable energy sources or reduce the consumption of the fossil fuels which end up affecting the environment as in global warning, depletion of the ozone layer, pollution, etc. It is in view of this that, any attempt to reduce the total energy requirement at any instant will be of great importance.

\section{Conclusion}

This paper present the importance of designing cooling systems in hot environment and the necessity to optimize this design with regards to electrical supplies to minimize cost of installation and maintenance. The methodology dealt with Fourier law that was applied to two scenarios including a cement wall and a cavity wall. Result showed that the cavity wall limits the amount of heat transfer considerably and therefore has been recommended for buildings that will sustain a good cooling system with some reduced electrical supply.

\section{References}

1. Beggs C, Beggs C (2009) Chapter 13-Energy Efficient Air Conditioning and Mechanical Ventilation. In Energy: Management, Supply and Conservation, pp. 252-287.

2. Solomon S, Qin D, Manning M (2007) Climate Change 2007 the Physical Science Basis. Intergovernmental Panel on Climate Change. Retrieved from Cambridge University Press, Cambridge, United Kingdom and New York, NY, USA, p. 996.

3. Bergasse E, Paczynski W, Dabrowski M, Wulf D (2013) the relationship between energy and socio- economic development in the Southern and Eastern Mediterranean. Warsaw, Germany.

4. Lejárraga I (2010) Roaring Tiger or Purring Pussycat: A Growth Diagnostics Study of Ghana. In Annual Meeting of the American Economic Association, Atlanta, USA, pp. 1-61.

5. Jendrizky G (1998) Impacts of Extreme and Persistent TemperatureCold Waves and Heat Waves. In WMO/UNESCO Sub-Forum on Natural Disaster Reduction, pp. 43-53.

6. WHO (1998) Health impacts of climate extremes.

7. Fernandez Milan B, Creutzig F, Milan F, Brondizio ES, Leemans, R, et al. (2015) Reducing urban heat wave risk in the 21st century. Current Opinion in Environmental Sustainability 14: 221-231.

8. Nayak JK., Prajapati JA (2006) Thermal Performance of Buildings. In: JK Nayak \& Prajapati JA (Eds.), Handbook on Energy Conscious Buildings, India, pp. 1-8.

9. Armenian HK., Carroll RJ, Ruppert D, Stefanski LA (1989) Measurement Error in Nonlinear Models. Atlanta Centers for Disease Control Monographs on Statistics and Applied Probability 7(63): 800-842.
Your next submission with Juniper Publishers will reach you the below assets

- Quality Editorial service

- Swift Peer Review

- Reprints availability

- E-prints Service

- Manuscript Podcast for convenient understanding

- Global attainment for your research

- Manuscript accessibility in different formats

( Pdf, E-pub, Full Text, Audio)

- Unceasing customer service

Track the below URL for one-step submission https://juniperpublishers.com/online-submission.php 